\title{
İkili Köprü Ayaklarında Temiz Su Oyulmasının Zamansal Gelişimi
}

\author{
Meriç YILMAZ ${ }^{1}$ \\ A. Melih YANMAZ ${ }^{2}$ \\ Mete KÖKEN ${ }^{3}$
}

$\ddot{O Z z}$

Alüvyonlu akarsu tabanına inşa edilen köprülerde, köprü ayaklarının emniyetli tasarımı için ayaklar etrafında oluşan maksimum oyulma derinliğinin pik tasarım debisine erişme süresine kadarki zamansal gelişimini incelemek gerekmektedir. Bu çalışmada, akım doğrultusuna paralel arka arkaya konumlanmış ikili köprü ayakları etrafında, temiz su ve üniform taban malzemesi koşullarında oluşan oyulma çukurunun yüzey özelliklerini incelemek amacıyla deneysel bir araştırma yürütülmüştür. Deneyler, değişik ayak çapı ve ayaklar arası mesafelerde ikili özdeş silindir ayaklar kullanılarak değişik akım şiddetleri ile gerçekleștirilmiștir. Çalıșmanın sonucunda, maksimum temiz su oyulmasının zamansal değişimini tahmin eden bir denklem üretilmiş̧ir. Deneylerin test aralığında, önerilen denklemin deneysel bulgularla uyum gösterdiği gözlenmiştir.

Anahtar Kelimeler: Köprü, orta ayak, grup etkisi, zaman, temiz su, oyulma.

\begin{abstract}
Time-Evolution of Clear Water Scouring at Dual Bridge Piers

Time evolution of the maximum scour depth around piers up to peak value of the design flow is required for safe foundation design of bridges crossing alluvial rivers. This study deals with an experimental work conducted to investigate the surface characteristics of scour-holes around dual piers aligned with the flow direction under clear water conditions with uniform bed material. Experiments are conducted using different sizes of identical cylindrical dual piers for different spacing and flow intensities. Eventually a scour-prediction equation is developed to determine the temporal variation of maximum clear water scour depth. In the test ranges of the experiments, the results of the proposed equation are found to be in relatively good agreement with the experimental results.
\end{abstract}

Keywords: Bridge, pier, group effect, time, clear water, scour.

\footnotetext{
Not: Bu yazı

- Yayın Kurulu'na 14.08.2015 günü ulaşmıştır. 18.04.2017 günü yayımlanmak üzere kabul edilmiştir.

- 31 Mart 2018 gününe kadar tartışmaya açıktır.

- DOI: $10.18400 /$ tekderg. 345263
}

1 Orta Doğu Teknik Üniversitesi, İnşaat Mühendisliği Bölümü, Ankara - smeric@metu.edu.tr 2 Orta Doğu Teknik Üniversitesi, İnşaat Mühendisliği Bölümü, Ankara - myanz@metu.edu.tr

3 Orta Doğu Teknik Üniversitesi, İnşaat Mühendisliği Bölümü, Ankara - mkoken@metu.edu.tr 
İkili Köprü Ayaklarında Temiz Su Oyulmasının Zamansal Gelişimi

\section{GíRiş}

Dünyada her yıl çok sayıda köprü orta ve kenar ayakları etrafında oluşan aşırı oyulma nedeniyle yıkılmaktadır. Bu durum hem can kaybına hem de olumsuz sosyo-ekonomik koşullara yol açmaktadır. Bu nedenle, bu konunun detaylı araştırılması diğer hidrolik odaklı konular arasında öncelik kazanmaktadır. Güvenli köprü ayak tasarımı için oyulma mekanizmasının anlaşılması bir önkoşuldur. Ancak, oyulma çukuru etrafındaki üç boyutlu ayrılmanın ve akım-ayak-taban malzemesi etkileşiminin karmaşık yapısı nedeniyle orta ayaklar etrafinda oluşan oyulma mekanizması bugüne kadar teorik olarak tamamen tanımlanamamıştır [1,2]. Böylece, yirminci yüzyılın ortalarından beri artan bir eğilimle bu konu çeşitli yönleriyle ele alınarak çoğunlukla laboratuvar ortamında araştırılmıştır [3]. Ayrıca, hem yeni tasarlanan köprülere hem de mevcut köprülere uygulanabilirlikleri göz önüne alınarak, çeşitli oyulma önleyici düzenlemelerin tasarımı da önem kazanmıştır. Bu nedenle, köprülerin aşırı oyulmaya bağlı yıkılma riskinin azaltılması amaçlanmıştır [4].

Yersel koşullarla uyumlu özel çözüm sunabilmek için tasarımın hidrolojik boyutu göz önünde bulundurulmalıdır [5]. Tasarım taşkın hidrografının niteliği, söz konusu havzanın özelliklerine ve hidro-meteorolojik koşullarına göre belirlenmektedir. Daha önceki çalışmalarda çoğunlukla kararlı akım koşulları altında tekil orta ayak etrafında oluşan denge oyulma derinliğinin belirlenmesi üzerinde durulmuştur. Oyulma derinliğinin kararsız akım koşulları altında belirlenmesi üzerine, bazıları Kothyari ve diğerleri (1992), Hager ve Unger (2010), Schillinger (2011) ve Kalantari (2014) tarafından yürütülen sınırlı sayıda çalışma bulunmaktadır $[6,7,8,9]$. Temiz su koşulları altında denge oyulma derinliğine, oyulma çukuru içindeki kaydırıcı ve tutucu kuvvetlerin birbirini dengelediği durumda erişilmektedir. Başlangıçta çok hızla gelişen oyulma çukuru, kararlı akım şartlarında zaman içinde asimtotik olarak değişerek dengeli koşullara ulaşmaktadır. Laboratuvar koşullarında bu süre birkaç günü bulmaktadır [10]. Ancak, doğada tasarım hidrografının pik süresi, denge koşuluna ulaşma süresi kadar uzun sürmemektedir [11]. Dolayısıyla, köprü ayağı temellerini temiz su oyulması koşullarında denge oyulma derinliğine göre tasarlamak, ayak temel derinliğini gereğinden yüksek hesaplamaya yol açabilir. Tasarım taşkın hidrografının pik değerine erişme süresi bilindiğinde, denge oyulma koşuluna kıyasla daha düşük oyulma derinlikleri ve dolayısıyla daha ekonomik çözümler elde edilebilir [1]. Yani, oyulma derinliğinin zamansal gelişiminin incelenmesi, köprü ayak temeli tasarımı için uygun bilgi sağlamaktadır. Geleneksel uygulamada oyulma derinliğinin zamansal değişimi, tasarım hidrografının pik değerine erişme süresi boyunca pik debi değerinin sabit olduğu varsayımıyla incelenmektedir. $\mathrm{Bu}$ yaklaşım, oyulma derinliği gelişiminin kararsız akım koşullarında modellenmesi durumuna göre daha güvenli tarafta kalmaktadır.

$\mathrm{Bu}$ çalışmanın amacı, akım doğrultusunda konumlanmış ikili orta ayaklar etrafındaki birleşik oyulma çukuru yüzey özelliklerinin zamansal değişimini incelemektir. Değişik ayak çapı ve ayaklar arası mesafelerde özdeş ikili ayaklar kullanılarak, temiz su koşullarında değişik akım şiddetleri ile deneyler gerçekleştirilmiştir. Böylece, ayaklar etrafındaki maksimum temiz su oyulması derinliğinin zamansal değişimini tahmin eden bir ampirik oyulma tahmin denklemi üretilmiştir. 


\section{2. İLGILİ LITERATÜRE GENEL BAKIŞ}

Tekil orta ayaklar etrafındaki oyulma derinliğinin zamansal değişimi üzerindeki öncü çalışmalar 20. yüzyılın ortalarına dayanmaktadır [12]. O zamandan beri en kapsamlı çalışmalardan biri Ettema (1980) tarafından yürütülmüştür [13]. Yanmaz ve Altınbilek (1991) tekil silindir ve kare kesitli ayaklarda temiz su oyulmasının zamansal değişimini tahmin eden yar1-ampirik bir model üretmiştir [1]. Model daha sonra silindir ayaklar için Yanmaz (2006) tarafından güncellenmiştir [14]. Bu model, temiz su koşullarında tekil silindir ayaklardaki oyulma çukuruna kütle korunum prensibinin uygulanmasına dayanmaktadır. Melville ve Chiew (1999), Ettema (1980) tarafindan yürütülen ve ilave yapılan deneylerin sonuçlarını kullanarak orta ayaklarda oyulmanın zamana bağlı gelişimi için bir yöntem geliştirmiştir $[11,13]$. Bu yöntem, denge zamanının, $t_{e}$, yani denge oyulma derinliğine ulaşma süresinin belirlenmesine dayanmaktadır.

Literatürde oyulma tahmin denklemleri çoğunlukla tekil ayaklar için üretilmiştir. Ancak, geoteknik ve yapısal gereksinimler doğrultusunda köprüler normalde orta ayak grupları ile tasarlanmaktadır. Orta ayaklar, akım doğrultusu boyunca arka arkaya veya akım doğrultusuna dik olarak yan yana gibi çeşitli dizilişlerle yerleştirilebilir. Ayak grubu yerleşimi matris düzeninde $i$ x $j$ olarak tanımlanabilir. Burada, $i$ akım doğrultusuna dik ayak sayısı, $j$ ise akım doğrultusuna paralel ayak sayısıdır. Komşu ayaklar arasında taban malzemesi yüklü akım etkileşimine bağlı ileri seviye karmaşıklıktan dolayı, ilgili literatürde oyulma üzerinde ayak grup etkisi hakkında sınırlı bilgi bulunmaktadır [15]. Ayak grupları üzerindeki eski deneysel çalışmalar, ayaklar arası mesafenin denge oyulma derinliği üzerine etkilerini incelemek amacıyla gerçekleştirilmiştir.

Bu makalenin geri kalanında akım doğrultusunda hizalanmış ayaklar $(1 \mathrm{x} j)$ etrafında oyulma mekanizması üzerinde durulmaktadır. Tekil ayak oyulmasında başlıca etkenler düşey akım, atnalı çevrintisi ve kuyruk çevrintisidir. Ancak, akım doğrultusunda hizalanmış ayaklar durumunda, güçlendirme, siperleme ve çevrinti saçınımı olarak tanımlanan ilave mekanizmalar oluşur [16].

Ön ayak etrafındaki oyulma derinliğini etkileyen mekanizma güçlendirme mekanizmasıdır. $\mathrm{Bu}$ mekanizmaya göre, ön ve arka ayaklar etrafındaki oyulma çukurlarının çakışması sonucunda ön ayaktaki oyulma derinliği artmaktadır. Tekil ayak durumunda, taban malzemesi oyulma çukurundan atnalı çevrintileri ile süpürülür ve mansap yönünde belirli bir mesafe boyunca taşınır. Daha sonra, yetersiz enerji nedeniyle mansap yönünde daha fazla taşınamayacağı için tabanda birikir. Ancak, arka ayak olması durumunda oyulma çukurları çakışabilir ve bu durum, ön ayağın çıkış yolunda taban seviyesinin ve eğiminin azalmasına yol açabilir (bkz. Şekil 1). Azalan taban seviyesi ve eğimi, oyulma çukurundan aşınan malzemenin daha az enerjiyle taşınabilmesine yol açar. Böylece, taban malzemesi ön ayak etrafındaki oyulma çukurundan kolayca taşınır ve ayağın memba yüzündeki oyulma derinliği, tekil ayak durumuna göreceli olarak artar. Güçlendirme mekanizmasının şiddeti, artan ayaklar arası mesafe ve akım açısı ile birlikte azalır [17].

Siperleme mekanizmasında, bir ön ayağın varlığı arka ayağın yaklaşım hızını düşürür. Böylece, ön ayak etrafından aşınan taban malzemesi, arka ayağın membaında birikir. $\mathrm{Bu}$ durum, akımın tabandan yukarıya ve arka ayağın etrafına yönlenmesine neden olur [2]. Yönlenen akım, arka ayağın atnalı çevrintilerinin kuvvetini düşürür. Dolayısıyla, azalan yaklaşım hızı ve kuvvetini yitiren atnalı çevrintileri, arka ayağın menbaında daha düşük 
oyulma derinliğine yol açar. Siperleme mekanizmasının etkinliği, ayaklar arası mesafe arttıkça giderek azalır ve sonra kaybolur.

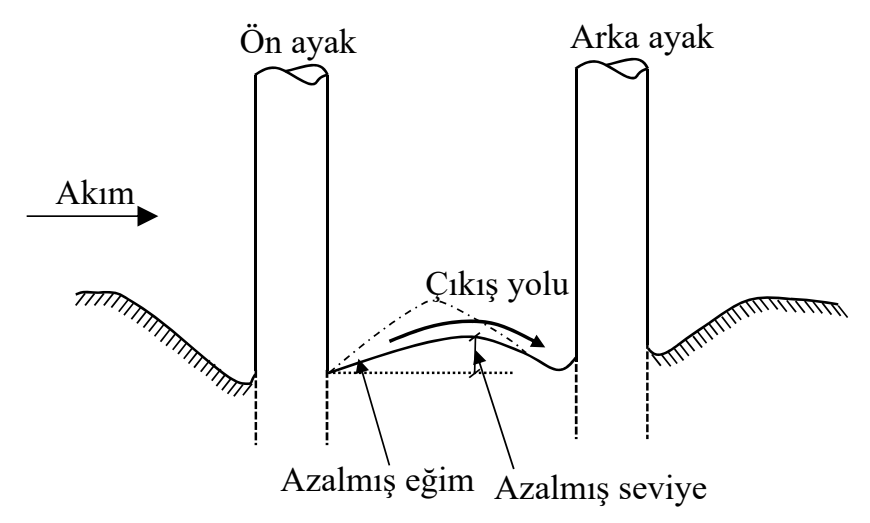

Şekil 1. Gü̧çendirme mekanizmasının şematik gösterimi [2]

Çevrinti saçınımı, taban malzemesinin arka ayak etrafından kalkmasına neden olur. Çevrintiler ön ayaktan saçıldığında, ayağın yanlarında yollar takip ederek mansap yönüne hareket ederler. Saçılan çevrintinin takip ettiği yolun arka ayakla mesafesi ve kuvveti, arka ayak etrafındaki oyulmanın şiddetini doğrudan etkiler. Ancak, akım doğrultusunda hizalanan ayaklar durumunda, arka ayak saçılan çevrintilerin izlediği yol ile çakışmaz. Bu nedenle, bu mekanizma çapraz konumlanmış ayaklarda olduğu kadar etkili değildir.

Akım doğrultusunda arka arkaya konumlamış ikili ayaklar $(1 \times 2)$ ve ayaklar arası mesafenin etkisi çeşitli araştırmacılar tarafından ele alınmıştır. Akım doğrultusuna paralel arka arkaya ve akım doğrultusuna dik yan yana dizilmiş ikili ayaklar etrafındaki oyulma derinliği Hannah (1978) tarafindan çeşitli ayaklar arası mesafelerde çalışılmış̧ır [16]. Deneylerin süresi 7 saat olarak belirlenmiş ve denge oyulma derinliğinin \%80'ine ulaşıldı ğ ifade edilmiştir. Akım doğrultusuna paralel konumlanmış ayaklarda, ön ayağın membaındaki oyulma derinliği, $d_{s}$, $\lambda=1$ iken tekil ayak durumu ile aynı bulunmuştur. Burada, $\lambda$ ayak çapının $(b)$ merkezden merkeze ayaklar arası mesafeye $(d)$ oranıdır. Ayaklar arası mesafe arttıkça $(\lambda<1)$, güçlendirme mekanizmasının etkisiyle $\lambda \approx 0.33$ iken maksimum $\mathrm{d}_{\mathrm{s}}$ değeri gözlenmiştir. Oyulma derinliği, bu maksimum değerinden azalan $\lambda$ değeri ile birlikte düșmüștür. Güçlendirme mekanizmasının etkisi, bu deneysel koşullar altında yaklaşık $\lambda<0.09$ değerine kadar sürmüştür. Ayaklar arası mesafe daha da arttığında, oyulma çukurlarının çakışması ortadan kalkmış, böylece oyulma derinliği tekil ayak durumu ile aynı bulunmuş ve ayaklar etrafinda birbirinden bağımsız oyulma çukurları oluşmuştur.

Nazariha (1996) değişik yerleşimli ayak grupları üzerinde deneyler gerçekleştirmiştir [2]. Çalışmada denge oyulma derinliğine ulaşmak amacıyla bazı deneylerin süresi 90 saat olarak alınmıştır. Daha sonra, tüm deneylerin süresi 2 saat olarak belirlenmiş ve bu süre sonunda görülen oyulma derinlikleri, 90 saatlik deneyler sonunda belirlenen bir katsayı ile çarpılarak denge oyulma derinliğine eşitlenmiş̧tir. Arka arkaya hizalanmış ayak yerleşiminde $\lambda \geq 0.2$ 
iken, ayaklar arası mesafenin, güçlendirme ve siperleme mekanizmalarının oyulma mekanizması üzerinde baskın olduğu gözlenmiş̧ir. Daha büyük $\lambda$ değerlerinde daha büyük oyulma derinliği elde edilmiştir.

Beg (2004) tarafından akım doğrultusuna paralel konumlanmış ayaklar için yapılan çalışmada, deney süresi 8 saat olarak belirlenmiş ve denge oyulma derinliğine ulaşıldığı ifade edilmiştir. Bu çalışmada, ön ayağın membaındaki oyulma derinliğinin $\lambda=0.33$ değerinde maksimuma ulaştığı, $\lambda=0.50$ değerinde ise $\lambda=0.33$ durumu ile neredeyse aynı derinliğe ulaştığı görülmüştür [18].

Ataie-Ashtiani ve Beheshti (2006) tarafindan yapılan benzer bir çalışmada, deney süreleri 7 saatin üzerinde tutulmuş ve denge oyulma derinliğine ulaşıldığı belirtilmiştir. Bu çalışmada ise, ön ayağın membaındaki oyulma derinliğinin farklı deneylerde $\lambda=0.33$ ve $\lambda=0.50$ değerlerinde maksimuma ulaştığı görülmüştür [15]. Ayrıca Ataie-Ashtiani ve Beheshti (2006), HEC-18 denklemi ve Melville ve Coleman (2000) denklemi için iki ayrı düzeltme çarpanı önermiştir $[15,19,20]$.

Ayak gruplarında ayaklar arası mesafenin etkisi Gao ve diğerleri (2013) tarafindan da çalışılmıştır [21]. Deney sürelerinin $9-12$ saat olarak belirlendiği çalışmada denge oyulma derinliğine ulaşıldığı ifade edilmiştir. Akım doğrultusuna paralel ayak gruplarında, ön ayağın membainda maksimum oyulma derinliğinin $\lambda=0.33$ değerinde gözlendiği belirtilmiştir.

Ayrıca, ayak grupları etrafında oyulma derinliğinin gelişimi üzerine Kim ve diğerleri (2014) sayısal bir çalışma gerçekleştirmiştir [22]. Sayısal model denge oyulma derinliği görülene dek çalıştırılmış ve 100 dakikada bu derinliğe ulaşıldığı belirtilmiştir. Ayaklar arası mesafenin etkisinin yanı sıra oyulma derinliğinin zamansal gelişimi de araştırılmıştır. Çalışmada, maksimum denge oyulma derinliğine $\lambda \approx 0.4$ değerinde ulaşıldığ belirtilmiştir.

Yukarıda bahsi geçen tüm çalışmalarda, akım doğrultusuna paralel konumlanmış ayak gruplarında, maksimum oyulma derinliğinin ön ayağın membannda görüldüğü ve ayaklar arası mesafenin bu derinliği etkilediği sonucuna varılmıştır. Bu makalede sadece konuyla doğrudan ilgili olan bilgi sunulmuştur. Köprü hidroliği kapsamında temel kavramlarla ilgili geniş bilgi için [23] numaralı kaynağa başvurulabilir.

\section{3. ÇALIŞMANIN KAPSAMI}

Giriş kısmında özetlenen hedefleri ortaya koymak amacıyla deneysel bir çalışma yapılmıştır. Deneyler, ön ve arka ayağın etrafında oluşan oyulma çukurlarının çakışacağı bir aralıkta, değişik ayaklar arası mesafeler ile gerçekleştirilmiştir. Bu çalışmanın nihai hedefi, yukarıda bahsedilen koşullarda ikili ayaklar etrafindaki maksimum oyulma derinliğinin zamansal değişimini hesaplayan ampirik oyulma tahmin denklemi üretmektir.

Literatürde, akım doğrultusuna paralel konumlanmış ayaklarda denge zamanını hesaplamak için açık bir denklem bulunmamaktadır. Bu nedenle, tekil ayaklarda temiz su oyulması için geçerli bir denklemi uygulamak, ikili ayak durumu için bir ön tahmin sağlayabilir. Bu amaçla, denge zamanı, $t_{e}$ Melville ve Chiew (1999) tarafından sı ̆̆ akımlar için önerilen Denklem (1) ile hesaplanabilir [11]. Bu çalışmanın deneysel koşulları kullanıldığında, denge zamanı laboratuvar ortamında 58 ila 93 saat olarak hesaplanmış olup, pek çok laboratuvar koşullarında kesintisiz olarak bu süreyle deneyleri gerçekleştirmek çok zordur. 


$$
t_{e}(\text { gün })=30.89 \frac{b}{u}\left(\frac{u}{u_{c}}-0.4\right)\left(\frac{d_{0}}{b}\right)^{0.25} \quad\left(\frac{d_{0}}{b} \leq 6\right)
$$

Burada, $u$ = ortalama yaklaşım akımı hızı, $u_{c}=$ tabanda hareketi başlatan ortalama yaklaşım akım hızı ve $d_{0}=$ yaklaşım akım derinliğidir. Bu çalışmada, oyulmanın başlangıç ve gelişme aşamalarının araştırılması planlanmış ve denge aşamasına yönelik bir çalışma yapılmamıştır. $\mathrm{Bu}$ yaklaşım, taşkının yükselme aşamasının çekilme aşamasından normalde daha kısa olmasından dolayı makuldür. Ayrıca, prototip koşullarda tasarım taşkının pik değerine erişme süresi, ilgili denge oyulma derinliğine erişme süresine kıyasla çok kısadır. Aslında, bu ilk iki gelişim aşamasının sonunda denge oyulma derinliğinin \%85 - \%95'ine ulaşılmaktadır [24]. Bu nedenle, deneylerde maksimum test süresi 6 saat olarak belirlenmiştir ve bu süre, doğada tekil pikli taşkınların çoğunun pik değere erişme süresi mertebesindedir [25].

\section{DENEYSEL ARAŞTIRMALAR}

Deneysel araştırma Orta Doğu Teknik Üniversitesi, İnşaat Mühendisliği Bölümü, Hidromekanik Laboratuvarı'nda gerçekleştirilmiştir. Deneylerde, uzunluğu $15.2 \mathrm{~m}$, genişliği $0.72 \mathrm{~m}$ ve derinliği $1.0 \mathrm{~m}$ olan dikdörtgen en-kesitli bir kanal kullanılmıştır (bkz. Şekil 2). Akım, ana kanala su deposundan giriş borusu yoluyla sağlanmıştır. Giriş borusu üzerine yerleştirilen ultrasonik akımölçer ile akımın debisi ayarlanmıştır. Giriş akımındaki türbülansı azaltmak amacıyla, kanalın membainda ilk $1.6 \mathrm{~m}$ uzunluğundaki havuz bölgesine çelik 1zgaralar yerleştirilmiştir. Bu bölgenin ardından $4.0 \mathrm{~m}$ uzunluğunda, 0.001 taban eğimli beton kısım gelmektedir. Kanalın test kısmına 0.3 m kalınlığında taban malzemesi döşenmiş ve beton kısımla bütünlük sağlayacak şekilde tabanı 0.001 eğime ayarlanmıştır. Test kısmında kullanılan taban malzemesinin medyan dane çapı, $D_{50}, 0.88 \mathrm{~mm}$ olup geometrik standart sapması 1.28'dir. Bu özellikler ile kullanılan taban mazlemesi üniform kabul edilmektedir [19]. Akım test kısmını geçtikten sonra malzemenin tutulduğu bir mansap havuzuna boşalmaktadır.

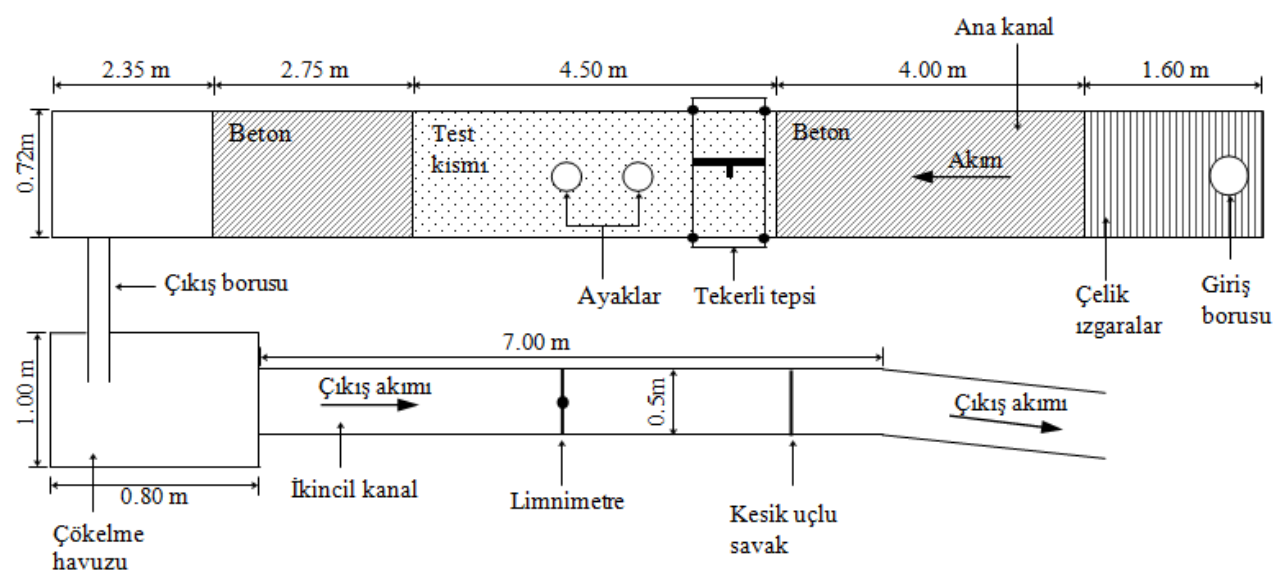

Şekil 2. Deney düzeneği 
Ayaklar etrafında taban seviyesinin ölçümü, 32 adet suya batık aktarıcıdan (transducer) oluşan SeaTek $5 \mathrm{MHz}$ Ultrasonik Mesafeleme Sistemi ile yapılmıştır. Sistem çıktı üretmek için bir iletişim programı olan CrossTalk ile anında etkileşimli çalışmaktadır. Deneylerde özdeş ikili ayak modelleri akım doğrultusuna paralel, arka arkaya yerleştirilmiştir. Ayak çapı, $b=7.5 \mathrm{~cm}, 6.3 \mathrm{~cm}$ ve $4.0 \mathrm{~cm}$ olmak üzere üç değişik silindir ayak modeli kullanılmıştır. Maksimum ayak çapı, deneylerde daralma oyulması oluşmaması için $7.5 \mathrm{~cm}$ olarak belirlenmiştir. Yanmaz'a (1989) göre, ayak çapının kanal genişliğine oranı olan daralma oranının \%10'dan az olduğu durumlarda, daralma oyulması ihmal edilebilir [26].

Deneylerde $d=2 b, 3 b$ ve $4 b$ olmak üzere üç değişik merkezden merkeze ayaklar arası mesafe sınanmıştır. Dolayısıyla test edilen ayak çapının ayaklar arası mesafeye oranı, $\lambda=0.25,0.33$ ve 0.50 'dir. Üç değişik akım şiddeti, $u / u_{c}=0.917,0.936$ ve 0.946 ile deneyler gerçekleştirilerek kanalda temiz su koşulları sağlanmıştır. Akım şiddetinde görülen $u_{c}$ değişkeni, aşağıdaki denklemler kullanılarak hesaplanmıştır [19]:

$u_{*_{c}}=0.0115+0.0125 D_{50}^{1.4}$

$$
\frac{u_{c}}{u_{*_{c}}}=5.75 \log \left(5.53 \frac{d_{0}}{D_{50}}\right)
$$

Burada $u_{* c}$ kritik kayma gerilmesi hızıdır. Deneysel koşullar Çizelge 1'de sunulmaktadır. Burada $Q$ akım debisi, $F_{d}=u /\left(\Delta g D_{50}\right)^{0.5}$ yoğunluk dane Froude sayıs1, $\Delta=\rho_{s} / \rho-1$ bağıl batmış yoğunluk, $\rho_{s}$ taban malzemesi yoğunluğu, $\rho$ su yoğunluğu ve $g$ yerçekimi ivmesidir. Çizelge 1'de görüldüğü üzere, çalışma kapsamında deneyler iki kısımda gerçekleştirilmiştir. Deneylerin birinci kısmında (PR1-PR6), ikili ayaklar etrafinda oyulma çukuru topografyasının zamansal değişimi elde edilmiştir. Çizelge 1'de \#, farklı zamanlarda ölçüm alınan deney tekrarlanma sayısını ifade etmektedir. Bu kısımda iki farklı $\lambda$ değeri ile $(\lambda=0.25$ ve 0.33) deneyler gerçekleştirilmiştir. Deneylerin ikinci kısmı ise (R1-R7) ön ayağın membainda görülen maksimum oyulma derinliğinin zamansal gelişimini elde etmek amacıyla yapılmıştır. Suya batık çalışan aktarıcı sisteminin genişliği nedeniyle en büyük ayak çapında tüm $\lambda$ değerleri ile deneyler yapılırken diğer ayak çaplarında sadece $\lambda=0.25$ ve 0.33 değerleri ile deneyler gerçekleştirilmiştir. Bu kısmın çıktıları, ikili ayaklar etrafındaki maksimum oyulma derinliğinin zamansal değişimini tahmin edecek ampirik denklemin üretiminde kullanılmıştır.

Çizelge 1. Çalışmanin deneysel koşulları

\begin{tabular}{lccccccc}
\hline Deney & $\#$ & $b(\mathrm{~cm})$ & $\lambda$ & $d_{0}(\mathrm{~cm})$ & $Q(\mathrm{lt} / \mathrm{s})$ & $u / u_{c}$ & $F_{d}$ \\
\hline PR1 & 11 & 7.5 & 0.33 & 5.50 & 12 & 0.946 & 2.54 \\
PR2 & 11 & 7.5 & 0.25 & 5.50 & 12 & 0.946 & 2.54 \\
PR3 & 6 & 6.3 & 0.33 & 5.50 & 12 & 0.946 & 2.54 \\
PR4 & 6 & 6.3 & 0.25 & 5.50 & 12 & 0.946 & 2.54 \\
PR5 & 6 & 4.0 & 0.33 & 5.50 & 12 & 0.946 & 2.54 \\
PR6 & 6 & 4.0 & 0.25 & 5.50 & 12 & 0.946 & 2.54 \\
\hline
\end{tabular}


İkili Köprü Ayaklarında Temiz Su Oyulmasının Zamansal Gelişimi

Çizelge 1. Çalışmanın deneysel koşulları (devam)

\begin{tabular}{lcccccc}
\hline Deney & $b(\mathrm{~cm})$ & $\lambda$ & $d_{0}(\mathrm{~cm})$ & $Q(\mathrm{lt} / \mathrm{s})$ & $u / u_{c}$ & $F_{d}$ \\
\hline R1-8 & 7.5 & 0.50 & 4.00 & 8 & 0.917 & 2.33 \\
R1-10 & 7.5 & 0.50 & 4.75 & 10 & 0.936 & 2.45 \\
R1-12 & 7.5 & 0.50 & 5.50 & 12 & 0.946 & 2.54 \\
R2-8 & 7.5 & 0.33 & 4.00 & 8 & 0.917 & 2.33 \\
R2-10 & 7.5 & 0.33 & 4.75 & 10 & 0.936 & 2.45 \\
R2-12 & 7.5 & 0.33 & 5.50 & 12 & 0.946 & 2.54 \\
R3-8 & 7.5 & 0.25 & 4.00 & 8 & 0.917 & 2.33 \\
R3-10 & 7.5 & 0.25 & 4.75 & 10 & 0.936 & 2.45 \\
R3-12 & 7.5 & 0.25 & 5.50 & 12 & 0.946 & 2.54 \\
R4-8 & 6.3 & 0.33 & 4.00 & 8 & 0.917 & 2.33 \\
R4-10 & 6.3 & 0.33 & 4.75 & 10 & 0.936 & 2.45 \\
R4-12 & 6.3 & 0.33 & 5.50 & 12 & 0.946 & 2.54 \\
R5-8 & 6.3 & 0.25 & 4.00 & 8 & 0.917 & 2.33 \\
R5-10 & 6.3 & 0.25 & 4.75 & 10 & 0.936 & 2.45 \\
R5-12 & 6.3 & 0.25 & 5.50 & 12 & 0.946 & 2.54 \\
R6-8 & 4.0 & 0.33 & 4.00 & 8 & 0.917 & 2.33 \\
R6-10 & 4.0 & 0.33 & 4.75 & 10 & 0.936 & 2.45 \\
R6-12 & 4.0 & 0.33 & 5.50 & 12 & 0.946 & 2.54 \\
R7-8 & 4.0 & 0.25 & 4.00 & 8 & 0.917 & 2.33 \\
R7-10 & 4.0 & 0.25 & 4.75 & 10 & 0.936 & 2.45 \\
R7-12 & 4.0 & 0.25 & 5.50 & 12 & 0.946 & 2.54 \\
\hline
\end{tabular}

\subsection{Oyulma Çukurlarının Zamana Bağlı Yüzey Özellikleri (I. Kısım Deneyler)}

Çalışmanın bu kısmında, arka arkaya konumlanmış ayaklar etrafındaki oyulma çukurunun üç boyutlu topografik haritaları elde edilmiştir. Bu haritalar, oyulma çukuru özelliklerinin zamana bağlı değişimi hakkında bilgi sağlamaktadır. Bu kısımdaki deneyler, temiz su koşullarında değişken akım şiddetlerinde benzer oyulma çukuru özellikleri oluşacağ sabit bir akım şiddetinde, $u / u_{c}=0.946$ ile gerçekleştirilmiştir. Deneyler düzlenmiş taban ile başlatılmışıır. Başlangıçta çıkış vanası kapatılmış ve taban malzemesinin bozulmasına olanak vermeden kanal yavaşça arzulanan yaklaşım akımı derinliğine ulaşana dek su ile doldurulmuştur. Giriş vanası ayarlanarak test debisine ulaşıldığında çıkış vanası tamamen açılmıştır. Deneyler, belirlenmiş ölçüm zamanlarında durdurularak üç boyutlu topografik haritalar elde etmek amacıyla ayaklar etrafındaki oyulma ve birikme bölgelerinde ölçümler alınmıştır. PR3-PR6 deney gruplarında, ölçüm zamanları 5, 20, 60, 100, 150 ve 360 dakikadır. PR1-PR2 deney gruplarında ise, daha büyük ayak çapı kullanıldığı için daha geniş oyulma çukuru beklenmektedir. Bu nedenle, daha geniş olan oyulma çukurunun zamansal gelişimini daha sık aralıklarla gözlemlemek amacıyla ölçüm zamanları 5, 10, 15, 20, 30, 45, $60,80,100,150$ ve 360 dakika olarak belirlenmiştir. Böylece, PR1-PR2 deney gruplarında 11, PR3-PR6 deney gruplarında ise 6 deney tekrarı yapılmıştır (bkz. Çizelge 1). Deneyler her 
ölçüm zamanında, taban batimetrisinin bozulmaması için yavaşça durdurulmuştur. Ölçüm alındıktan sonra kanaldaki suyun boşaltılıp tabanın düzleştirilmesi ile en baştan tekrar edilen deney bir sonraki ölçüm zamanına kadar devam ettirilmiștir. Deneylerin en sonundaki (360 dakika) oyulma çukuru topografyası da haritalandıktan sonra kanaldaki su boşaltılmıştır. Bir sonraki deney grubu için, ayak çapı ve/veya ayaklar arası mesafe değiştirilip test kısmına yerleştirildikten sonra taban düzleştirilip deney ve haritalama işlemi tekrar edilmiştir.

Anılan zamanlarda $(t)$ yapılan ölçümler kullanılarak 46 adet zamana bağlı topografik harita üretilmiştir. Örnek olarak, PR3 deney grubunun $t=5,60$ ve 360 dakikadaki topografik haritaları Şekil 3'te sunulmuştur. Şekilde $x$ ve $y$, sirasıyla akım doğrultusuna paralel ve dik koordinatı gösterirken, $z$ kanal tabanına dik koordinattır. Şekil 3 'te görüldüğü üzere, tekil ayaklar etrafında oyulma çukurunda olduğu gibi, ikili ayaklar etrafında oyulma çukuru sınırları da plan görüntüde atnalı şekline benzemektedir. Şekil 3 'te sunulan PR3 deney grubu ile beraber tüm deney gruplarında, oyulmanın başlangıç kısımlarında atnalı şekli tamamen oluşmasa da, $t=60$ dakikadan sonra şekil daha belirgin hale gelmekte ve deneylerin sonunda atnalı şekli açıkça görülmektedir.

Topografik haritalardan, akım doğrultusunda merkez eksen boyunca oyulma çukurunun profil görüntüsü elde edilmiştir. Örnek olarak, PR1 deney grubunda, taban profilinin zamana bağlı değişimi Şekil 4'te görülebilir. Şekilde görüldüğü üzere, maksimum oyulma derinliği her zaman ön ayağın membainda oluşmaktadır. Tüm deneylerde maksimum oyulma derinliği bu bölgede oluşmuştur. İkili ayaklarda, mütemadi temel gereksinimi dikkate alınacak olursa, ön ayağın memba yüzündeki maksimum oyulma derinliğinin belirlenmesi oldukça önemlidir. Böylece, bu ölçümler deneylerin ikinci kısmının kapsamını oluşturmaktadır.

Şekil 4'te görüldüğü üzere, ayakların arasında bir birikme bölgesi oluşmaktadır ve bu bölgenin pik noktasının yeri, akım doğrultusu boyunca zamansal olarak sabit kalmaktadır. Pik nokta ile arka ayağın merkezi arasındaki mesafe, ayaklar arası mesafenin $(d)$ yüzde oranı olarak hesaplanmıştır. PR1 deney grubu için, birikme bölgesinin pik noktası ile arka ayağın merkezi arasındaki mesafe $d$ değerinin \%37'sine eşittir. PR2 deney grubunda, yani aynı ayak çapı fakat farklı $\lambda$ oranı kullanıldığında ise, ilgili mesafe $d$ değerinin \%38'ine eşit bulunmuştur. Bu mesafenin ilgili $d$ değerine oranı PR3 ve PR4 deney gruplarında sırasıyla $\% 39$ ve $\% 35$, PR5 ve PR6 deney gruplarında ise sırasıyla $\% 34$ ve $\% 33$ olarak bulunmuştur. Dolayısıyla, ayak çaplarına göre deney bulguları incelenirse, birikme bölgesinde pik noktasının yerinin, $\lambda$ değerinden neredeyse bağımsız olduğu kabul edilebilir. Arka ayağın mansabında ise bir başka birikme bölgesi oluşmaktadır. Bu bölge, deneylerin başlangıcında, yani oyulma hızının yüksek olduğu zamanda nispeten daha diktir. Bu birikme bölgesi zaman içinde mansap yönüne ilerlemekte ve yassılaşmaktadır (bkz. Şekil 4). PR1 deney grubunda bu birikme bölgesinde yapılan gözlemler, diğer deney gruplarında da aynı şekilde gözlenmiştir.

Ön ayağın membaında, ön ayağın mansabında (ayağın mansap yüzünden ayaklar arası birikme bölgesine kadar), arka ayağın membannda (ayaklar arası birikme bölgesinden ayağın memba yüzüne kadar) ve arka ayağın mansabında (ayağın mansap yüzünden mansap birikme bölgesine kadar) boyuna taban eğimleri zaman içinde sabit kalmaktadır. Ön ve arka ayağın membanndaki taban eğimleri neredeyse birbiriyle aynı olup yaklaşık olarak taban malzemesinin iç sürtünme açısına eşittir. Ayrıca, ayakların mansap taban eğimleri de yine birbirine eşittir. Dolayısıyla, akım doğrultusuna paralel ikili ayaklar etrafındaki birleşik oyulma çukuru şeklinin zamandan bağımsız olduğu söylenebilir. 
İkili Köprü Ayaklarında Temiz Su Oyulmasının Zamansal Gelişimi
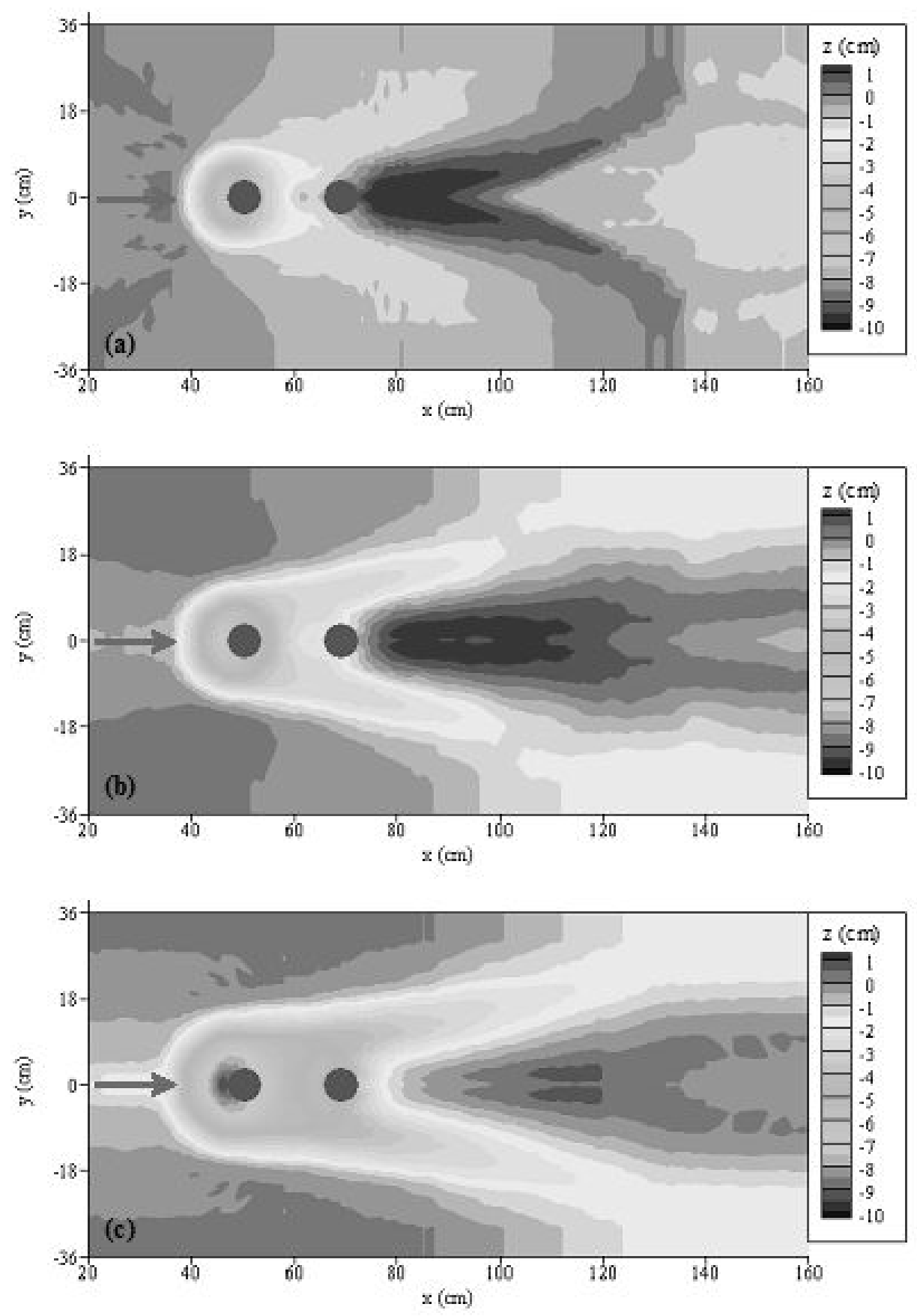

Şekil 3. PR3 deney grubunun topografik haritaları (a) $t=5 \mathrm{dak}$, (b) $t=60$ dak ve (c) $t=360 \mathrm{dak}$ 


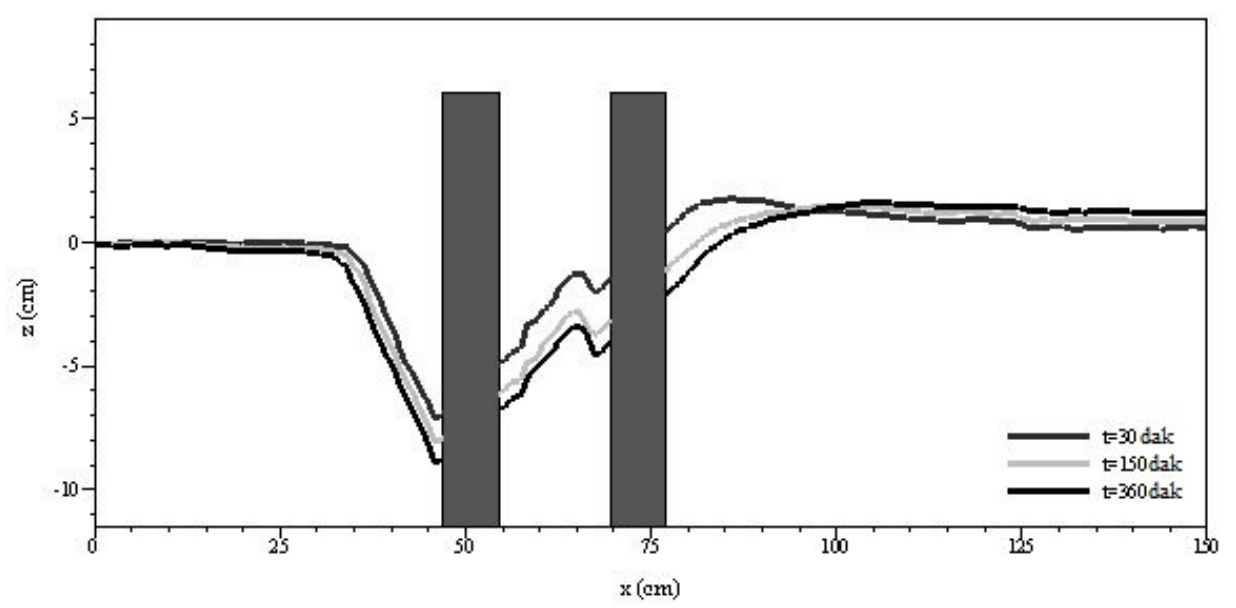

Şekil 4. PR1 deney grubunun merkez eksen boyunca taban profili

\subsection{Kısım Deneyler}

Deneysel çalışmanın bu kısmında, ikili ayaklarda maksimum oyulma derinliğinin gelişimini daha sık aralıklarla ölçmek amaçlanmıştır. Bu çalışmada, oyulma derinlikleri ön ayağın membainda ve yanal ekseninde, arka ayağın ise sadece yanal ekseninde ölçülmüş̧ür. Ancak, daha önce belirtilen nedenlerden ötürü, ampirik modelin oluşturulmasında sadece maksimum oyulma derinliğinin zamansal değişimi ölçümleri kullanılmıştır. Çizelge 1'de belirtilen deneysel koşullar altında, 21 adet deney gerçekleştirilmiş ve maksimum oyulma derinliklerinin sık ölçümleri alınmıştır. Deneylerde gözlendiği üzere, maksimum oyulma derinliğinin gelişimi, oyulma olayının başlangıcında çok hızlıyken, zaman içinde yavaşlamakta ve asimtotik olarak denge durumuna yaklaşmaktadır. Bununla beraber, belirli bir akım şiddetinde $\left(u / u_{c}\right)$ ve $\lambda$ değerinde, maksimum oyulma derinliğinin ayak çapı büyüdükçe yükseldiği açıkça gözlenmiştir. Ayrıca, belirli bir $b$ ve $\lambda$ değerinde, maximum oyulma derinliği artan akım şiddeti ile beraber yükselmektedir. Belirli $b$ ve $u / u_{c}$ değerinde ise, maksimum oyulma derinliği artan $\lambda$ değeri ile beraber yükselmektedir (güçlendirme mekanizmas1).

Her iki ayağın yanal eksenlerindeki oyulma derinliğinin zamansal değişimini, ön ayağın membanda görülen maksimum oyulma derinliği ile kıyaslamak amacıyla, örnek olarak R112 deneyinin ölçümleri Şekil 5'te sunulmuştur. Arka ayağın yanal ekseninde oyulma derinliklerinin, siperleme mekanizmasına bağlı olarak her zaman ön ayağın membannda ve yanal eksenindeki oyulma derinliklerinden daha az olduğu gözlenmiştir. Ön ayağın yanlarında oluşan çevrintiler akımla beraber süpürüldükleri için, bu çevrintilerin aşındırma kapasiteleri ayağın membaına kıyasla daha azdır. Bu nedenle, ön ayağın yanal eksenindeki oyulma derinlikleri her zaman aynı ayağın membaına kıyasla daha düşük çıkmaktadır. Eksenlerdeki oyulma derinliği farklılıkları, tüm deneylerde benzer şekilde gözlenmiştir. 


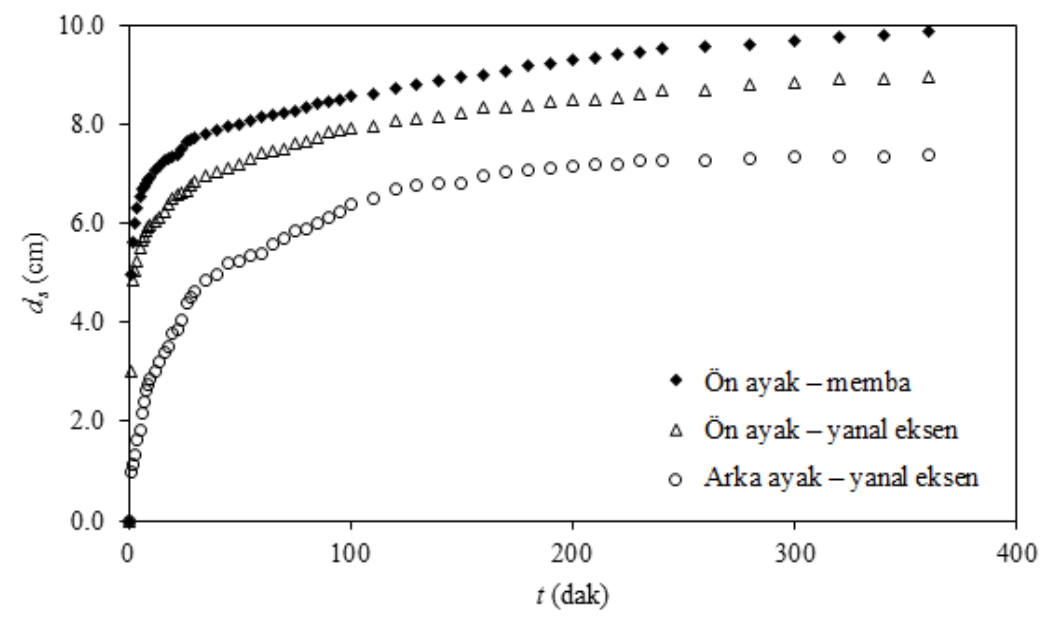

Şekil 5. R1-12 deneyinin değişik eksenlerde oyulma derinliklerinin kuyaslanması

\section{DENEY SONUÇLARININ DEĞERLENDİRILLMESI}

Arka arkaya konumlanmış ayak yerleşiminde, güçlendirme mekanizmasının şiddeti $\lambda$ değerine bağlıdır. I. Kısım Deneylerde, $\lambda$ değerinin güçlendirme mekanizması üzerindeki etkisi gözlenmiş, $\lambda=0.33$ değerinde daha yüksek maksimum oyulma derinlikleri elde edilmiş ve $d_{s}$ değerinin tüm ayak çapları için $\lambda=0.25$ durumunda azaldığı gözlenmiştir. II. Kısım Deneylerin sonuçları I. Kısım ile uyumlu olup, $b=6.3 \mathrm{~cm}$ ve $4.0 \mathrm{~cm}$ ayak çapları için $\lambda=$ 0.33 değerinde ölçülen maksimum oyulma derinlikleri, $\lambda=0.25$ durumuna kıyasla daha yüksek bulunmuştur. En büyük ayak çapı için $\lambda=0.33$ ve 0.25 değerlerinde benzer eğilim gözlenmiş, en fazla oyulma derinliği ise $\lambda=0.50$ değerinde görülmüştür. Özetle, bu çalışmada maksimum oyulma derinliği $\lambda=0.50$ durumunda en yüksek seviyeye ulaşmakta ve $\lambda$ değeri azaldıkça oyulma derinliği de azalmaktadır. Bu noktada, literatürde çoğunlukla $\lambda$ $\approx 0.33$ değerinde en yüksek oyulma derinliği gözlenirken bu çalışmada daha büyük bir $\lambda$ değerinde gözlenmesine, ayak çapının kanal genişliğine oranındaki farklılıkların neden olduğu düşünülmektedir. Literatürde bahsi geçen çalışmalarda ayak çapı kanal genişliğinin \%3.6-6.6'sında seyrederken bu çalışmada bu oran \%5.6-10.4'tür. Dolayısıyla, akım alanını nispeten daha fazla daraltan ayaklar birbirine daha yakın konumlandığında, çevrintilerin girişiminin daha etkili olacağı ve oyulma derinliğinin daha fazla artacağı beklenmektedir.

Ön ayağın varlığı nedeniyle, oyulma olayında siperleme mekanizması gerçekleşmektedir. Siperleme mekanizması, ön ayağın membanndaki oyulma derinliklerinin aynı ayağın mansabındaki oyulma derinliklerinden fazla olduğu gözlenen I. Kısım Deneylerde açıkça görülmektedir (bkz. Şekil 4).

II. Kısım Deneylerin sonuçlarından yola çıkarak ön ayağın membaındaki maksimum oyulma derinliğini hesaplamak için çoklu doğrusal regresyon denklemi üretilmiştir. Oyulma olayında yer alan ana parametreleri bağımsız değişken olarak kullanarak, Denklem (4)'te verilen regresyon denklemi elde edilmiş ve determinasyon katsayısı, $R^{2}$ Denklem (5) kullanılarak 0.84 olarak hesaplanmıştır: 


$$
\begin{aligned}
& \frac{d_{s}}{b}=0.081\left(\frac{d_{0}}{b}\right)^{0.155}\left(F_{d}\right)^{2.357}\left(T_{s}\right)^{0.123}(\lambda)^{0.102} \\
& R^{2}=\left[\frac{\sum_{i=1}^{n}\left(m_{i}-\bar{m}\right)\left(p_{i}-\bar{p}\right)}{\sqrt{\sum_{i=1}^{n}\left(x_{i}-\bar{x}\right)^{2}} \sqrt{\sum_{i=1}^{n}\left(p_{i}-\bar{p}\right)^{2}}}\right]^{2}
\end{aligned}
$$

Burada, $T_{s}=t D_{50}\left(\Delta g D_{50}\right)^{0.5} / b^{2}$ boyutsuz zaman olup daha önce orta ayak oyulma modellemesinde kullanan Yanmaz ve Altınbilek (1991), Dey (1996) ve Yanmaz (2006) ile benzer şekilde hesaplanmıştır [1, 14, 27]. Denklem (5)'te $m_{i}$ ve $\bar{m}$ sırasıyla deneylerde ölçülen oyulma derinlikleri ve bu değerlerin ortalaması iken, $p_{i}$ ve $\bar{p}$ sırasıyla Denklem (4) ile hesaplanan oyulma derinlikleri ve bu değerlerin ortalamasıdır. Farklı akım şiddeti, ayak çapı ve ayaklar arası mesafe koşullarını temsil eden denklemin determinasyon katsayısı oldukça yüksektir. Denklem (4) medyan dane çapı $D_{50}=0.88 \mathrm{~mm}$ olan taban malzemesi ve $\lambda$ değerinin $0.25-0.50$ aralığında olduğu durumlar için geçerlidir. Deneysel ölçülen oyulma derinlikleri Denklem (4) sonuçları ile kıyaslanmıştır. Makale boyutunu büyütmemek için, örnek olarak sadece sekiz deneyin sonuçları grafik ortamında kıyaslanmış ve Şekil 6'da sunulmuştur. Denklem (4) ile hesaplanan ampirik denklem sonuçları, $\Delta=1.65$ değerine sahip kuvars kum tabanda, deneysel çıktılar ile tatmin edici seviyede uyumludur. Denklem (4) kullanılarak Şekil 6'da sunulan eğrilerin saçılma indisleri ( $S I)$ Denklem (6) ile hesaplanmıştır ve bu değerler sırasıyla şöyledir: (a) 0.04, (b) 0.05, (c) 0.04, (d) 0.05, (e) 0.04, (f) 0.05, (g) 0.06 ve (h) 0.06 . Bu değerlerin oldukça küçük olması, test verisinin uyum çizgisi etrafinda kümelendiğini göstermektedir. Yine Şekil 6'da sunulan deneylerin hata standart sapmaları (HSS) ise Denklem (7) ile hesaplanmıştır ve bu değerler sirasıyla şöyledir: (a) 0.02, (b) 0.03, (c) 0.04 , (d) 0.03 , (e) 0.04 , (f) 0.06 , (g) 0.08 ve (h) 0.06 . Burada, $d_{s} / b$ boyutsuz parametresinin en düşük ve en yüksek değer aralığının genişliği göz önünde bulundurulduğunda, hesaplanan hata standart sapma değerleri (0.02-0.08) göreceli olarak oldukça düşüktür.

$$
\begin{aligned}
& S I=\frac{\left[\sqrt{\left.\frac{\sum_{i=1}^{n}\left(p_{i}-\bar{p}\right)^{2}}{n-1}\right]^{2}}\right.}{\bar{p}} \\
& H S S=\frac{\left[\sum_{i=1}^{n}\left(m_{i}-p_{i}\right)-\overline{\left(m_{i}-p_{i}\right)}\right]^{2}}{n-1}
\end{aligned}
$$

Literatürde, ikili ayak gruplarında önceden yapılan çalışmaların bulguları ile Denklem (4)'ün kıyaslanması mümkün olmamıştır. Zira, önceki çalışmalarda denge oyulma derinliğine ulaşılmış veya yaklaşılmışken mevcut çalışmada oyulmanın başlangıç ve gelişme aşamaları içinde zamansal gelişimi üzerinde durulmuştur. Literatürde oyulmanın zamansal gelişimi üzerinde durulan sayısal çalışmada [22] ise 100 dakikada denge oyulma derinliğine ulaşıldığı ifade edilmiş olup bu süre fiziki model koşullarında gerçek dışıdır; dolayısıyla bir kıyaslama yapılmamıştır. Benzer çalışmalar gelecekte yapıldığı takdirde, mevcut çalışmanın bulguları ile bir karşılaştırma imkanı olacaktır. 
İkili Köprü Ayaklarında Temiz Su Oyulmasının Zamansal Gelişimi
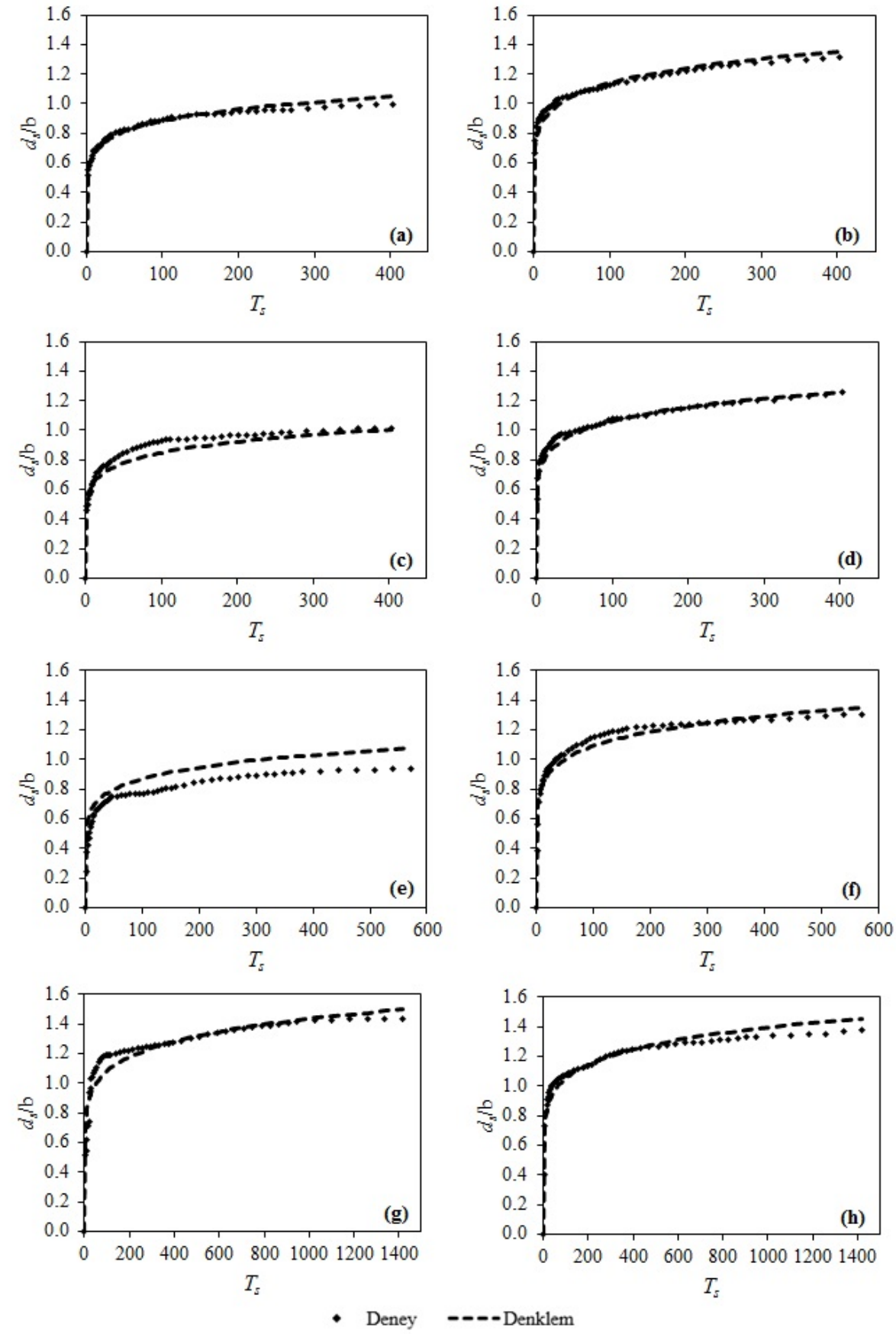

Şekil 6. Deneysel veriler ve bunlardan elde edilen oyulma tahmin denkleminin klyaslaması

(a) R1-8, (b) R1-12, (c) R2-8, (d) R3-12, (e) R4-8, (f) R5-12, (g) R6-10 ve (h) $R 7-10$ 


\section{SONUÇ}

Akım doğrultusuna paralel konumlanmış ikili silindir ayaklar etrafında maksimum temiz su oyulması derinliğini hesaplamak için bir ampirik denklem üretilmiştir. Deneyler üniform dağılımlı taban malzemesi kullanılarak, üç değişik ayak çapı ve üç değişik ayaklar arası mesafede gerçekleştirilmiştir. Bu çalışmanın sonuçları şöyledir:

Arka arkaya konumlanmış ikili ayaklarda maksimum oyulma derinliği her zaman ön ayağın memba yüzünde oluşmaktadır. Ön ayağın yanal eksenindeki oyulma derinlikleri aynı ayağın memba yüzündeki oyulma derinliklerinden, arka ayăğı yanal eksenindeki oyulma derinlikleri ise ön ayağın memba ve yanal eksenindeki oyulma derinliklerinden her zaman daha düşüktür. Belirli akım şiddeti ve $\lambda$ değerinde, maksimum oyulma derinliği ayak çapı büyüdükçe artmaktadır. Ayrıca, belirli ayak çapı ve $\lambda$ değerinde, maksimum oyulma derinliği akım şiddeti büyüdükçe artmaktadır. Ek olarak, belirli ayak çapı ve akım şiddetinde, maksimum oyulma derinliği $\lambda$ değeri büyüdükçe artmaktadır. Bu durum, ayak gruplarında güçlendirme mekanizmasının bir sonucudur. Ayrıca, güçlendirme mekanizması kuvvetinin $\lambda$ değeri azaldıkça düştüğü gözlenmiştir. Arka ayağın membaındaki oyulma derinliği, ön ayağın mansabına kıyasla her zaman daha düşüktür. Bu durum, ayak gruplarında siperleme mekanizmasının sonucudur. Ayaklar arasında birikme bölgesinin pik noktası zaman içinde yer değiştirmemektedir. Her iki ayağın da memba ve mansabında boyuna taban eğimleri zaman içinde sabit kalmaktadır. Ayakların memba taban eğimleri birbiriyle neredeyse aynı olup yaklaşı olarak taban malzemesinin iç sürtünme açısına eşittir. Ayakların mansap taban eğimleri de yine birbirine neredeyse eşittir. Böylece, arka arkaya konumlanmış ikili ayaklar etrafında birleşik oyulma çukuru şeklinin zamandan bağımsız olduğu kabul edilmiştir. Ampirik denklemin $\lambda$ değeri için önerilen uygulama aralığ $0.25-0.50$ 'dir. Deneysel verilerden türetilen ampirik denklem deney sonuçları ile karşılaş̧ırılmıştır. Ampirik denklemin zamana bağlı maksimum oyulma derinliği için tatmin edici tahminler sunduğu görülmüştür.

\section{Semboller}

$b$ = ayak çapı;

$D_{50}=$ medyan dane çapı;

$d \quad=$ merkezden merkeze ayaklar arası mesafe;

$d_{0}=$ yaklaşım akım derinliği;

$d_{s}=$ oyulma derinliği;

$F_{d}=$ yoğunluk dane Froude sayısı;

$g$ = yerçekimi ivmesi;

$H S S=$ hata standart sapmasi;

$i=$ akım doğrultusuna dik ayak sayısı;

$j=$ akım doğrultusuna paralel ayak sayısı;

$m_{i} \quad=$ deneylerde ölçülen oyulma derinlikleri; 


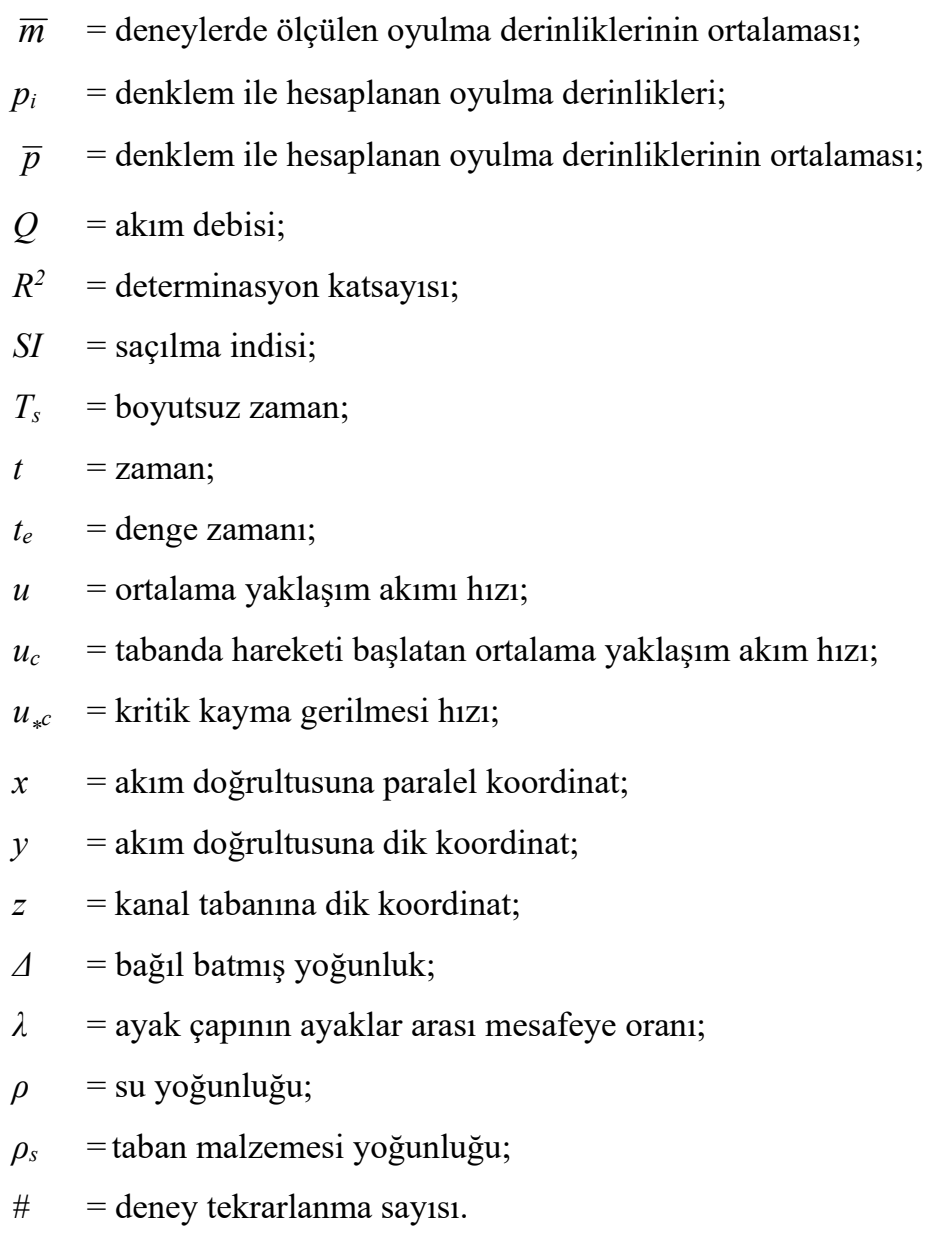

\section{Kaynaklar}

[1] Yanmaz, A. M., Altınbilek, H. D.,Study of time dependent local scour around bridge piers. Journal of Hydraulic Engineering, 117(10), 1247-1268, 1991.

[2] Nazariha, M., Design relationships for maximum local scour depth for bridge pier groups. PhD thesis, University of Ottawa, Ottawa, Canada, 1996.

[3] Köse, Ö., Yanmaz, A. M., Scouring reliability of bridge abutments. Turkish Chamber of Civil Engineers Digest 2010, 21, 1387-1402, 2010.

[4] Yanmaz, A. M., Apaydın, M., Bridge scour risk assessment and countermeasure design. Journal of Performance of Constructed Facilities, 26(4), 499-506, 2012.

[5] Yanmaz, A. M., Coşkun, F., Hydrological aspects of bridge design: Case study. Journal of Irrigation Engineering, 121(6), 1-8, 1994. 
[6] Kothyari, U., Garde, R., Ranga Raju, K., Temporal variation of scour around circular bridge piers. Journal of Hydraulic Engineering, 118(8), 1091-1106, 1992.

[7] Hager, W. H., Unger, J., Bridge pier scour under flood waves. Journal of Hydraulic Engineering, 136(10), 842-847, 2010.

[8] Schillinger, M., Temporal pier scour evolution under stepped hydrographs. MSc thesis, University of Clemson, SC, 2011.

[9] Kalantari, O., Time-dependent local scour of circular bridge pier. PhD thesis, The Graduate College at the University of Nebraska-Lincoln, NE, 2014.

[10] Breusers, H. N. C., Nicollet, G., Shen, H. W., Local scour around cylindrical piers. Journal of Hydraulic Research, 15(3), 211-252, 1977.

[11] Melville, B., Chiew, Y., Time scale for local scour at bridge piers. Journal of Hydraulic Engineering, 125(1), 59-65, 1999.

[12] Chabert, J., Engeldinger, P., Etude des affouillements autour des piles de ponts. Laboratoire National d'Hydraulique, Chatou, France, 1956.

[13] Ettema, R., Scour at bridge piers. Rep. No.216, 1980.

[14] Yanmaz, A. M., Temporal variation of clear water scour at cylindrical bridge piers. Canadian Journal of Civil Engineering, 33(8), 1098-1102, 2006.

[15] Ataie-Ashtiani, B., Beheshti, A. A., Experimental investigation of clear-water local scour at pile groups. Journal of Hydraulic Engineering, 132(10), 1100-1104, 2006.

[16] Hannah, C. R., Scour at pile groups. Research Rep. No. 28-3. Civil Engineering Dept., Univ. of Canterbury, Christchurch, New Zealand, 1978.

[17] Hosseini, R., Amini, A., Scour depth estimation methods around pile groups. KSCE Journal of Civil Engineering, 00(0000), 1-13, 2015.

[18] Beg, M., Mutual interference of bridge piers on local scour. Proc. of ICSE2, Singapore, 111-118, 2004.

[19] Melville, B. W., Coleman, S. E., Bridge scour. Highlands Ranch, Colorado, USA: Water Resources Publications, 2000.

[20] Richardson, E. V., Davis, S. R., Evaluating scour at bridges. Hydraulic Engineering Circular No:18, Report No: FHWA NHI 01-001, FHWA, US. Dept. of Transportation, Washington, D.C, 2001.

[21] Gao, P., Duan, M., Zhong, C., Yuan, Z., Wang, J., Current induced scour around single piles and pile groups. Proc. of 23rd International Offshore and Polar Engineering, Alaska, USA, 9, 472-477, 2013.

[22] Kim, H. S., Nabi, M., Kimura, I.,Shimizu, Y., Numerical investigation of local scour at two adjacent cylinders. Advances in Water Resources, 70, 131-147, 2014.

[23] Yanmaz, A.M. Köprü hidroliği, Ankara: ODTÜ Yayıncıllk, 2002.

[24] Hoffmans, G.,Verheij, H. J., Scour manual. Rotterdam, Netherlands: Balkema, 1977. 
İkili Köprü Ayaklarında Temiz Su Oyulmasının Zamansal Gelişimi

[25] Selamoğlu, M., Modeling temporal variation of scouring at dual bridge piers. $\mathrm{PhD}$ thesis, Middle East Technical University, Ankara, Turkey, 2015.

[26] Yanmaz, A. M., Time-dependent analysis of clear-water scour around bridge piers. PhD thesis, Middle East Technical University, Ankara, Turkey, 1989.

[27] Dey, S., Sediment pick-up for evolving scour near circular cylinders. Applied mathematical modelling, 20(7), 534-539, 1996. 